\title{
Physical activity on prescription
}

\section{Leif Hultén*}

Department of Surgery Colorectal Unit, Sahlgrenska University Hospital SU/Ö, 41685 Göteborg Sweden

There is no other sport but golf so well suited for ageing people - and that so well combines recreation, excitement, regular physical activity, recreation, encouraging self-training and pleasant social relations. Unfortunately, the golf sport, which in the U.S. is a real popular sport for the masses, is in Sweden still quite wrongly perceived as a "snob sport for upper class people". This seems to be a prejudice deeply rooted even in political circles.

Golf can in fact be seen as a cheap and popular sport. A clubset, which will last a lifetime, costs about 200 euro - a trifle compared to what the average person spends on such TV, video, sailboards and season tickets at Gym. Balls match the price of any beer - a price that is hardly difficult to pay even for pensioners. Annual charges should be kept below the cost of such for a municipal berth, a TV license or Gym. Golfing can continue southward almost daily basis for 8-10 months / year, 5-6 month in the north, which means an insignificant expenditure at a time of interesting and healthy recreation. Both in our country, as elsewhere, it is common for people to play golf in high ages, 80-90 year old.

Golf courses, correctly buildt, is extremely scenic landscape features, far preferable to arable land or fields, spruce plantations, etc. Why not use any. "Surplus land" for the construction of golf courses with increased recreational opportunity for people of ages who especially need it, also associated with good returns, more jobs and contribution to natural beauty? Actually, every home for the elderly should have a golf course of their own outside their gate, precisely for these reasons!

Within 10-15 years, 20-25\% of our people will be old-age pensioners, and everything done to keep this large group physically and mentally fit and active would reduce the overall social and medical care costs. Pure profit in a larger perspective - but one has to discard prejudices about the so-called "rich man's sport" in the first place and instead to emphasize the medical benefits of physical activation and recreation such as golf does.

Apart from creating general subjective well-being, the sport has beneficial effect on most of the body's organs and its functions even from a strictly medical scientific viewpoint. It is well known that regular physical activity has positive effects on health in both men and women of all ages. The risk of dying a premature death is reduced, particularly the risk of developing or dying from coronary heart disease. Sedentary people are at twice the risk of dying from such cardiac death compared with physically more active. A half hour walk a day is considered by the World Health Organization (WHO) and National Institutes of Health (NHI) enough to improve health and reduce the risk of premature death. Additional health benefits are obtained if one increases further the daily amount or intensity of physical activity. An 18-hole round of golf takes a few hours and gives especially on a cubic perad path significantly more exercise than a regular half-hour walk. Muscles and joints in the arms, legs and back activated by increased blood flow and the lungs get good oxygenation. In addition, lower blood lipids and decreased blood pressure, increased insulin sensitivity with reduced risk of "clotting" (thrombosis)as well as heart rhythm abnormalities.

After an hour of muscle work also activated the endogenous endorphin the release of endorphins which creates that välgöran- the mental relaxation and general well-being as follows a round of golf. Evidence found that physical activation linked to endorfinsys-system also strengthens the immune system. Favorable effects of high blood pressure, digestion problems and mental imbalance and stress is also attributed to endorphine release.

"Physical activity on prescription" is introduced by the Swedish National Health Institut as an age-and individualized writing-able prescription of physical activity for patients who need to increase or alter their physical activity for prevention or treatment of disease. The golf sport should fit in well with this prescription.

With this background should politicians, both at the national and municipal level, to free themselves from prejudices about "the expensive snob sport" and promptly propagate - especially for our growing older population - for this recreational sport that is both mentally and physically stimulating and easy even to individualize both to extent and pace. Golf should be placed high on the list of health care - and should be given generous support from the government and the local authories.

Golf: a game of life and death -reduces mortality in Swedish golf player.

Fahrman B, et al. Scand J, Medicine \& Science in Sports 2009.

\section{Conclusion}

Mortality in the golf group was about $40 \%$ less than that in the control group. A $40 \%$ reduction in mortality might correspond to an increase in life expectancy of about 5 years.

${ }^{*}$ Correspondence to: Leif Hultén, MD., PhD, Professor em. FACS,SFKRK (Hon), ACGBI (Hon), ISUCRS (Hon), SICCR (Hon), Dept. Surgery Colorectal Unit, Sahlgrenska University Hospital SU/Ö, 41685 Göteborg Sweden, Tel: +46(0)704943610; E-mail: leif.hulten@surgery.gu.se, leif.hulten@gmail.com

Received: June 12, 2020; Accepted: July 20, 2020; Published: July 23, 2020

Copyright: $(\mathbb{C} 2020$ Hultén L. This is an open-access article distributed under the terms of the Creative Commons Attribution License, which permits unrestricted use, distribution, and reproduction in any medium, provided the original author and source are credited. 